\title{
Matrix Converter Bi-directional Switch Power Loss and Cooling Condition Estimation for Integrated Drives
}

\author{
Alvis Sokolovs, Riga Technical University, Ilya Galkin, Riga Technical University
}

\begin{abstract}
In this paper power loss estimation of bi-directional switch of matrix converter is done by means of calculation and experiments. For safe operation of power devices an efficient cooling system of specific device must be designed. This work is part of a greater project of integrated matrix converter AC drives and the cooling problem here is viewed in context of this task. It is necessary to develop a compact power board and cooling system to extract excessive heat from power devices.
\end{abstract}

Keywords: power losses, power semiconductor switches, matrix converter, integrated AC Drives

\section{INTRODUCTION}

Matrix converters have been considered as an alternative to conventional PWM converters for frequency control in $\mathrm{AC}$ drives. Classical matrix converter (MC) consists of nine bidirectional switches that are arranged in such a way that any input phase can be connected to any output phase (Fig. 1.). This topology was proposed by Gjugyi and Pelly [1], more research was done by Venturini [2], [3]. With technological progress semiconductors become smaller with greater performance. This allows integration for power converter inside an electrical machine. Higher integration level of electrical drives can be considered in application where motor and inverter separate installation is obstructive. It has been proposed to integrate $\mathrm{MC}$ in $\mathrm{AC}$ machine since $\mathrm{MC}$ does not contain bulk reactive components [4].

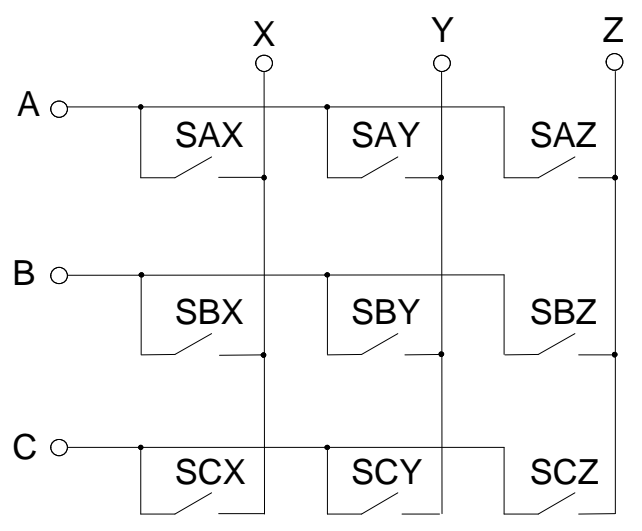

Fig. 1. Classical 3x3 Matrix Converter topology.

\section{POWER LOSSES OF BI-DIRECTIONAL SWITCH}

The key feature of a bi-directional switch is its capability of conducting current and blocking voltage in both directions.
Since there are no bi-directional switches available on the market, but these devices can be produced for custom order. However development of such devices is expensive and in most cases bi-directional switch is composed of discrete elements.

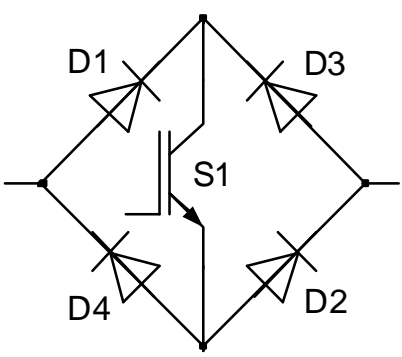

Fig. 2. Diode bridge bi-directional switch configuration.

In Fig. 2 a simple bi-directional switch configuration with diode bridge is presented. It implements only one switching device and a diode bridge configuration. The collector of the IGBT is connected to the anodes of the bridge, and the emitter is connected to the cathodes. Only one active switching element makes this a very attractive solution from point of view of costs and complexity of gate drive circuits. However there are two considerable disadvantages related to this circuit. It is impossible to control the direction of the current flow and there are relatively high conduction losses due the series connection of three semiconductor devices in each conduction path.

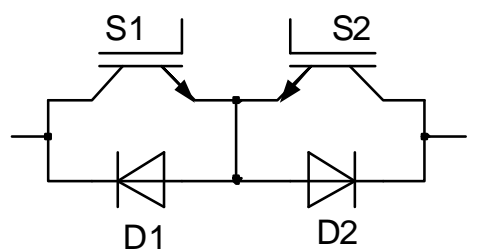

Fig. 3. Common emitter bi-directional switch.

More common bi-directional switch arrangement is common emitter IGBT connection (Fig. 3.). It implements two series connected IGBTs and two parallel diodes that ensure higher reverse voltage blocking capability of IGBTs. This configuration has lower conduction losses due to lack of one diode in the conduction path compared to diode bridge configuration. Second, it is possible to independently control 
current direction that allows safe commutation of inductive load current and reduce commutation losses [5]. For more efficient space usage IGBTs with built in anti parallel diodes can be used.

As in any commutated converter power losses in $\mathrm{MC}$ consist of conduction losses and commutation losses. Conduction losses are proportional to forward voltage drop of across the semiconductor device and the current flowing through the device. The forward voltage drop is dependent on the current flowing through the device and its junction temperature. These relationships require an iterative calculation since the device losses and the junction temperatures are interdependent [5]. Conduction losses per switch are calculated as the sum of conduction loss in IGBT and in corresponding diode. That is why conduction losses in MC are slightly higher compared to conventional voltage source inverters.

Commutation losses in IGBT occur due to finite switching time during which device changes its state. Commutation losses are proportional to commutation frequency at which device operates. And these losses are junction temperature dependent that makes iterative loop between losses and junction temperature more complex.

\section{POWER LOSSES IN MATRIX CONVERTER}

It is assumed that commutation time of IGBT compared to conduction time is negligible. In this case losses for one output phase of MC can be calculated as conduction losses in each phase (1).

$$
\begin{gathered}
P_{\text {loss phcon }}=\sum_{n=1}^{3}\left(\left(V_{C E S n} \cdot I_{C n} \cdot d_{n}\right)+\left(V_{f n} \cdot I_{f n} \cdot d_{n}\right)\right) \approx \\
\approx I_{f} \cdot\left(V_{C E S}+V_{f}\right),
\end{gathered}
$$

where $V_{C E S}$ - IGBT collector-emitter saturation voltage, $I_{C}$ - IGBT collector current, $V_{f}$ - diode forward voltage, $I_{f}-$ average diode forward current, $d_{n}-$ duty cycle for the $n$-the period of PWM.

Commutation losses per switch in MC are calculated as product of commutation frequency and total switching energy loss:

$$
P_{\text {logg com }}=3 \cdot f_{\text {com }} \cdot E_{\text {con tot }}
$$

The total power loss of MC is sum of commutation losses and conduction losses:

$$
P_{\text {loss tot }}=3 \cdot\left(P_{\text {loss ph con }}+P_{\text {loss com }}\right)
$$

The total power loss of each component of one bidirectional switch of MC as a function of frequency is shown in Fig. 4. These graphs are calculated in MATLAB for particular case of $0.3 \mathrm{~kW}$ converter using STGB10NC60HD IGBT transistors with integrated ultra-fast-recovery antiparallel diode.

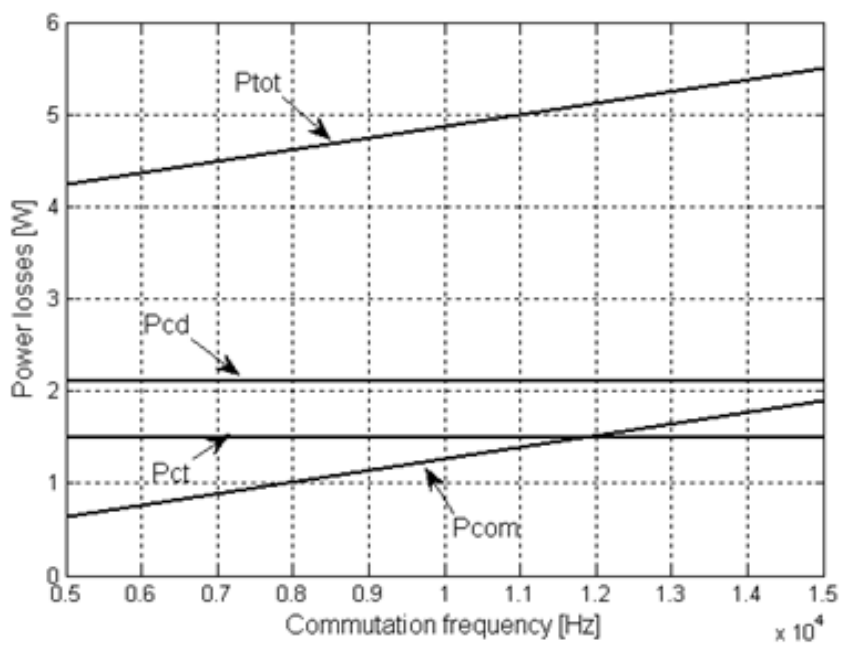

Fig. 4. Power losses of Matrix Converter where Ptot - total power loss, Pcom - comutation power loss, Pct - transistor conduction loss, Pcd - diode conduction loss.

In total converter power loss calculation it is assumed that commutation losses occur at every current path change. In [5] a method of reducing the converter losses is proposed. It is achieved by reduction of number of the switch state changes that produce switching losses.

\section{THERMAL CONSIDERATIONS}

Loss calculations are essential for determination of cooling conditions of the converter. Too much excessive heat due to losses will destroy transistor junction, but over dimensioned cooling system does not allow compact design of converter. This is why a tradeoff between good cooling and compact design must be found.

To determine cooling conditions of MC maximum allowable case temperature must be calculated. Temperature difference between case and junction is calculated as product of total power loss in the transistor $P_{\text {loss tot }}$ and junction-case thermal resistance $R_{t h j c}$ :

$$
\Delta T_{j e}=P_{\text {losstot }} \cdot R_{\text {th je}}
$$

Because junction-ambient thermal resistance is of much higher value than junction-case it is neglected here.

Maximal junction temperature is determined by properties silicon crystal. For power devices this temperature is determined to be form $125{ }^{\circ} \mathrm{C}$ to $150{ }^{\circ} \mathrm{C}$.

For safe operation $125{ }^{0} \mathrm{C}$ is used in this calculation. Maximum case temperature is calculated as:

$$
T_{o \max }=T_{j \max }-\Delta T_{j o},
$$

where $T_{c \max }$ - maximal case temperature, $T_{j \max }-$ maximum junction temperature. 


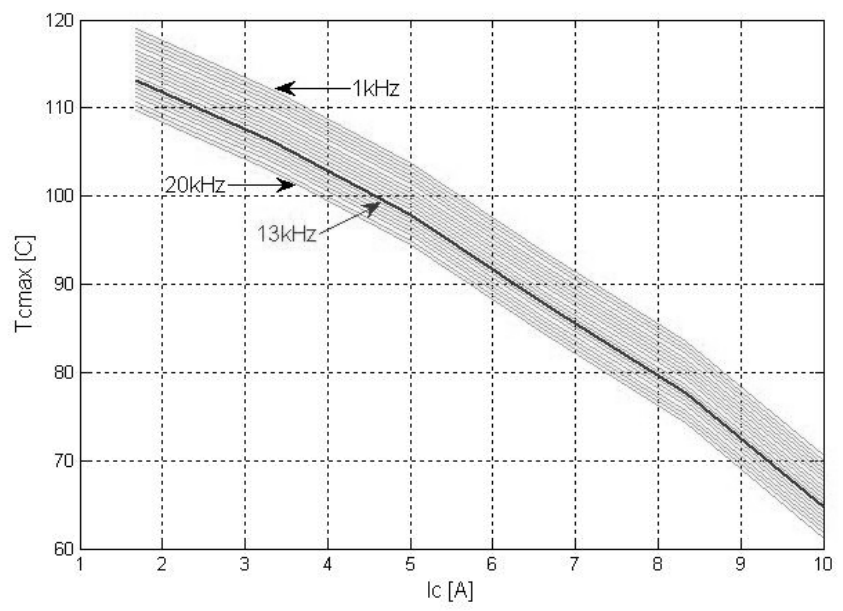

Fig. 5. Thermal limitations according to collector current and commutation frequency.

Graph in Fig. 5 illustrates maximal case temperature dependency on transistor collector current at different commutation frequencies. The higher commutation frequency the higher commutation losses of the transistor, hence lower the maximum case temperature is allowable.

\section{V.SIMULATION}

To estimate approximate power losses of IGBT a simulation in PSpice was done. Because there is no STGB10NC60HD model available at $S T$ homepage, a transistor model with higher current ratio is used (STGB7NC60HD). However despite the fact that the real device has built in ultra fast diode, the model does not have this element. To run simulation with conditions as close to real life as possible, an ultra fast diode with similar parameter is chosen.

Simulation conditions: input DC voltage $-200 \mathrm{~V}$, collector current - 1A, load inductance $4 \mathrm{mH}$, commutation frequency $13 \mathrm{kH}$, duty cycle -0.5 .

The simulation results $\left(\mathrm{V}_{\mathrm{CE}}, \mathrm{I}_{\mathrm{C}}\right.$ and their product, representing the instantaneous power loses) are presented in Fig. 6. The averaging of this product over the switching period gives the total power losses of $1.41 \mathrm{~W}$.

\section{EXPERIMENTS}

To verify simulation results, experiments with a common emitter bi-directional switch in chopper mode were done. Measured instantaneous switch collector-emitter voltage $-V_{C E}$ and collector current $-\mathrm{I}_{\mathrm{C}}$ are presented in Fig.7.

The obtained data produce the average power losses of about $3,14 \mathrm{~W}$. This is 2.2 times more than what simulation results have shown. Case temperature was also captured (Fig. 8.a.). Transistor that commutates load current has higher case temperature (Fig. 8.a. left) than transistor where only diode conducts (Fig. 8.a. right). However in MC the conduction is determined by output current polarity hence in each sine wave period each switch conducts in both directions and power losses are distributed equally in both devices.

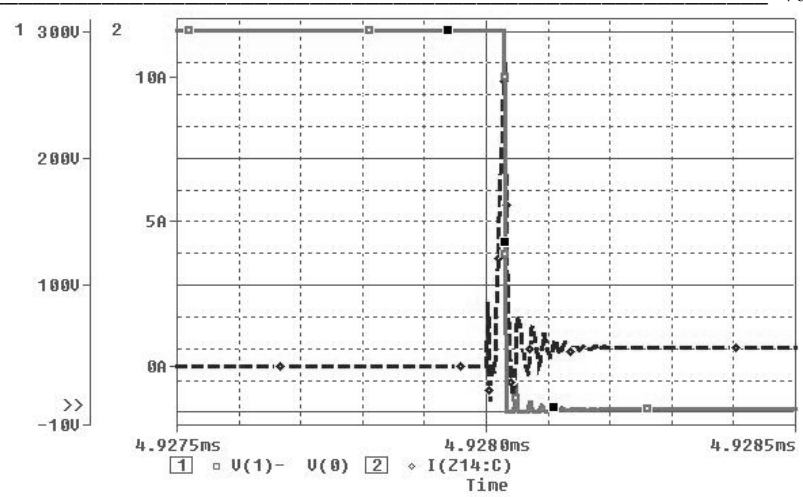

a)

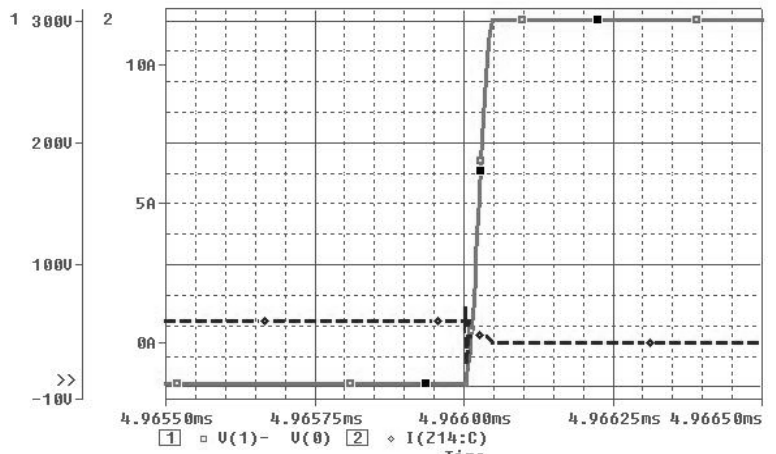

b)

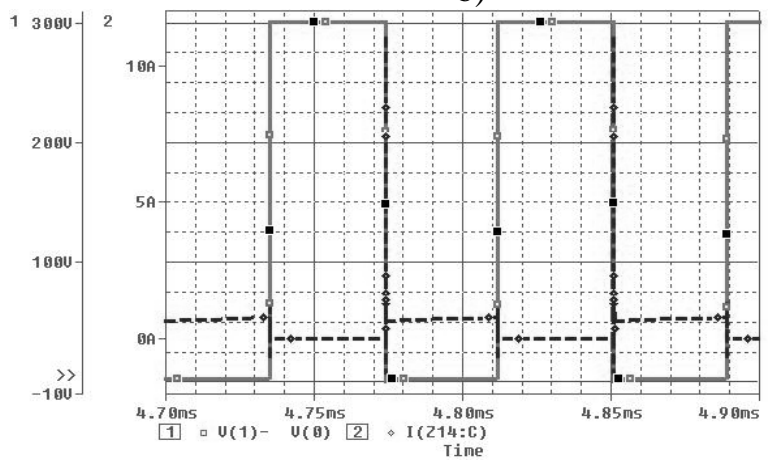

c)

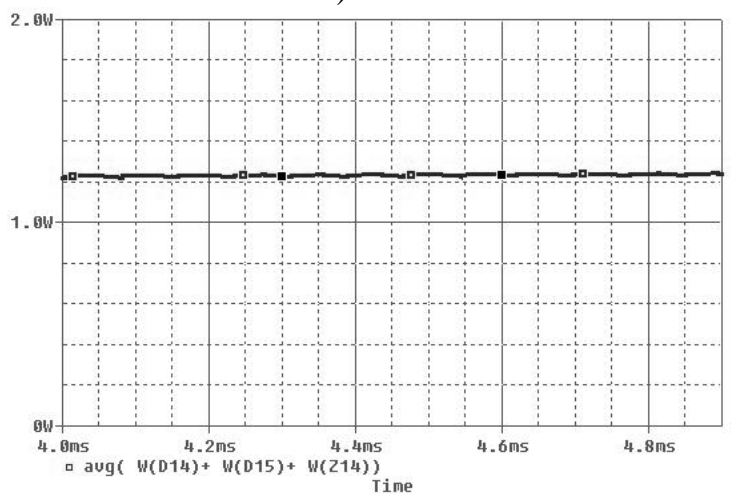

d)

Fig. 6. PSpice simulation of one bi-directional switch a) turn-on; b) turn-off; c) two commutation cycles; d) averaged total power losses (collector-emitter voltage - solid line, collector current - dashed line). 


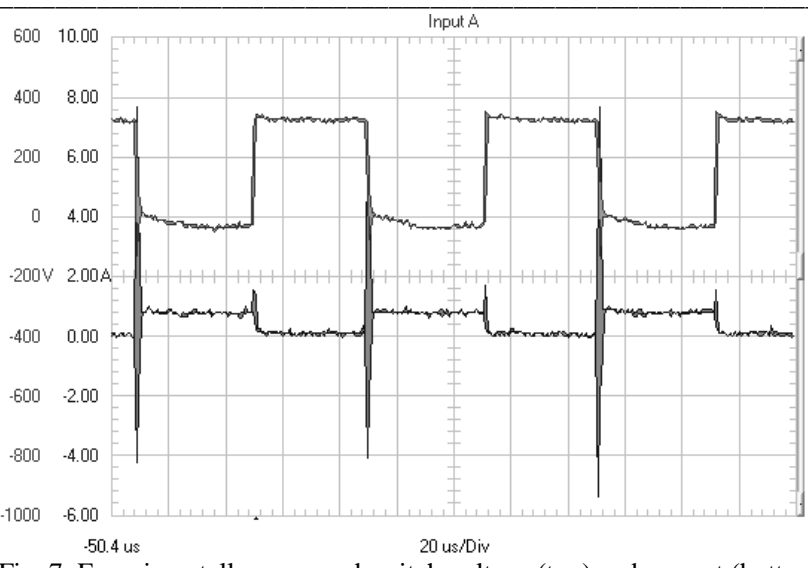

Fig. 7. Experimentally measured switch voltage (top) and current (bottom).

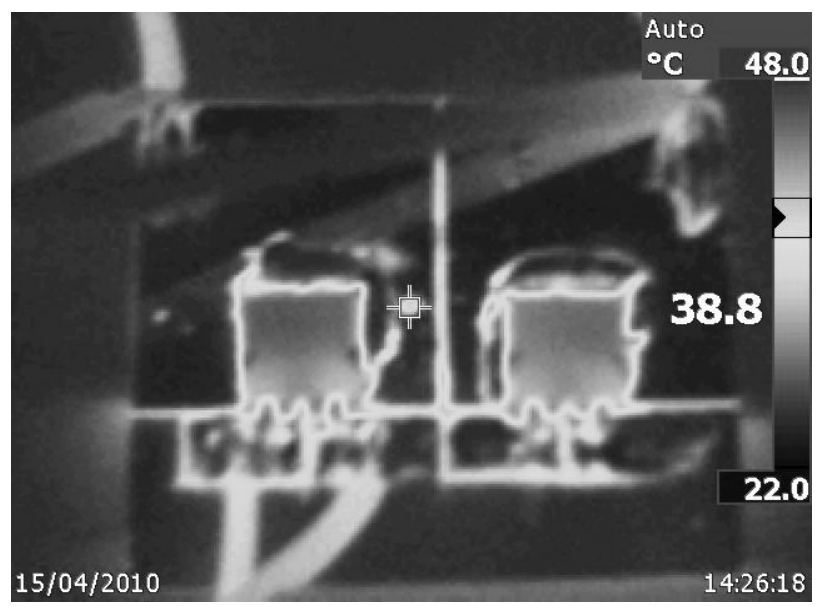

a)

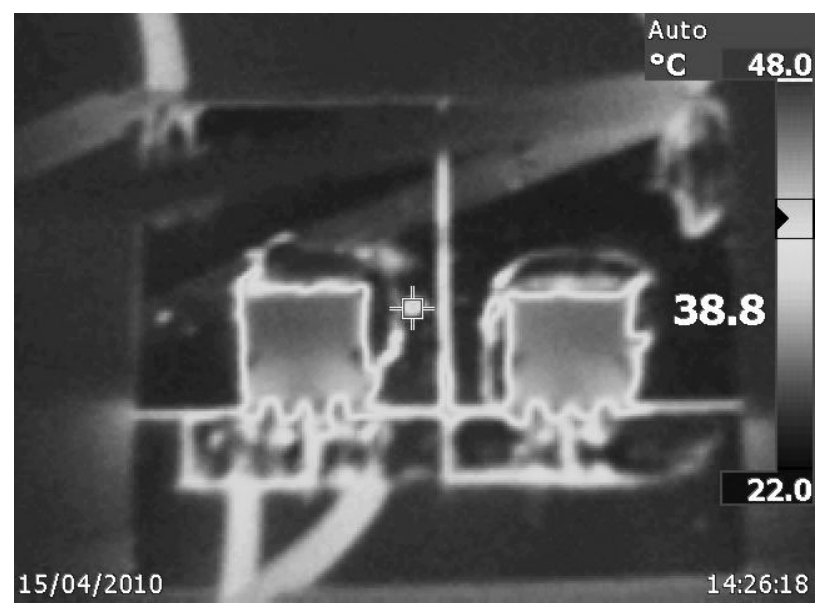

b)

Fig. 8. Temperature of a) bi-directional switch at $1 \mathrm{~A}$ at commutation frequency $13 \mathrm{kHz}$; b) back side of PCB.

\section{CONCLUSIONS}

Power loss and case temperature estimation of one bidirectional switch of matrix converter is done. Power losses in the switch were calculated, simulated and experimentally measured. The simulation results do not agree with experiments. This error can occur due to imprecision and idealized of simulation model. The obtained experimental data provides quite good practical base for further investigation and will be used in research of thermal design of integrated matrix converter AC drive.

\section{REFERENCES}

[1] Gjugyi L. and Pelly B., "Static Power Frequency Changers". New York, Wiley, 1976

[2] Venturini M., "A New Sinewave In Sinewave Out, Conversion Technique Which Eliminates Reactive Elements". Proceedings Powercon 7, 1980, pp.E3-1-E3-15.

[3] Alesina A. and Venturini M., "Intrinsic Amplitude Limits and Optimum Design of 9-switches Direct PWM AC to AC Converter", Proceedings of PESC Conference Record, 1980, pp.242-252.

[4] P. W. Wheeler, J. C. Clare, L. Empringham, K. J. Bradley, S. Pickering, D. Lampard, M. Apap, A Fully Integrated 30kW Motor Drive Using Matrix Converter Technology, $36^{\text {th }}$ IEEE Power Electronics Specialists Conference, 2005, pp. 2390-2395.

[5] P. W. Wheeler and D. A. Grant, Reducing the Semiconductor Losses in a Matrix Converter, IEE Colloquium on Variable Speed Drives and Motion Control, 1992, pp. 1-5.

Alvis Sokolovs received Bachelor's Degree in Electrical engineering at Riga

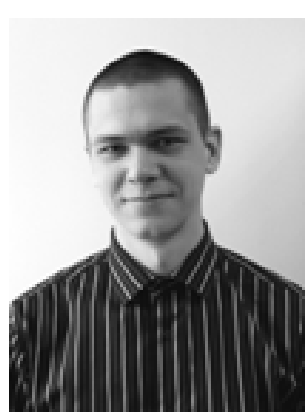
Technical University in 2004. In 2006 received Masters Degree in Electrical engineering at Riga Technical University. Currently he is doing PhD studies at department of Power and Electrical Engineering. Main research fields concern power electronics for electrical drives, active gate drive circuits for power IGBTs, electromagnetic compatibility and integrated electrical drives. He is author of following publications:

"Simulation Methods for $3 \times 3$ Matrix Converter", A. Sokolovs, I. Galkins, O. Krievs, J. Laugis, in IEEE proceedings of EPE-PEMC 2006http://www.portoroz.si/EN/;

"Possible construction of bus bars for matrix converter", A. Sokolovs, I. Galkin, in proceedings of EPQU 2007;

„800 V DC-DC power supply for gate driver of a common two transistor leg of VSI", A. Sokolovs, I. Galkin, Doctoral school of energy- and geotechnology 2009, Estonia.

Currently Alvis works as a researcher at Institute in Industrial Electronics and Electrical Engineering in Riga Technical University.

Ilya Galkin received his Bachelor's (1994), Master's (1996) and Doctor's

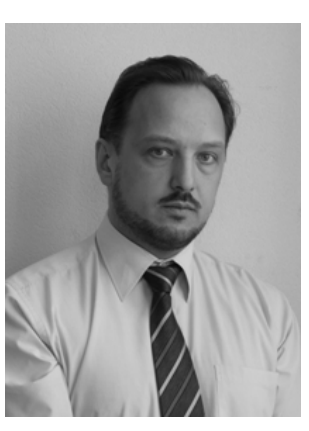
(2001) Degrees in the field of electrical engineering at Riga Technical University, Faculty of Power and Electrical Engineering, Department of Power Electronics and Electrical Technologies. The main research field includes design and applications of matrix converters. In particular it regards integrated designs with the matrix converters, smart control of their semiconductor switches, thermal and conductor's design. Another research field includes smart power supplies for various applications, for example, for LED lighting and uninterruptible power supplies.

The working experience of Ilya Galkin includes 6 year of practical engineering job at research and manufacturing enterprise "Lasma" (Latvia) in the field of elaboration and development industrial automatics, as well as 14 years of research and educational job at Riga Technical University. At the given time he is professor at the Department of Power Electronics and Electrical Technologies of RTU-EEF-IEEI. Ilya Galkin is the author of various publications.

Ilya Galkin is IEEE member since 2006 in societies of Power Electronics, Industrial Electronics, Automatic control and Education. 